\title{
Practical Dilemma and Path Innovation of Social Governance: A Case Study of Land Expropriation in China
}

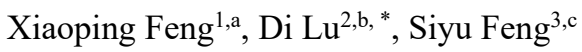 \\ ${ }^{1}$ School of Grammar and Economics, Wuhan University of Science and Technology, Wuhan, China \\ ${ }^{2}$ School of Grammar and Economics, Wuhan University of Science and Technology, Wuhan, China \\ ${ }^{3}$ Hubei Non-profit Organization Center, Wuhan, China
}

\begin{abstract}
In the "Internet+" era, conflicts of land requisition frequently occur. Existing research emphasizes the lack of systems but rarely considers the problems in the implementation of the system. Based on "Internet+", this article adopts a case analysis method to discuss the governance of land requisition conflicts. This study analyzes the contradictions in the implementation of land acquisition, benefit distribution, procedures and information feedback. The dilemma of social governance stems from the "autonomous space", "three-dimensional competition" and "independent space" of local governments. The innovation path of social governance needs to emphasize the supervision and regulation in the implementation of the system, the optimization of the system and the setting of the system and the flexible setting of the local field.
\end{abstract}

\section{Introduction}

The "2013 Social Blue Book" issued by the Chinese Academy of Social Sciences pointed out: In recent years, there have been tens of thousands or even more than 100,000 social conflicts that erupted every year due to various social contradictions. Even in 2016, the overall situation has not been fundamental. Transformation has also developed new forms such as online and offline, highlighting the real dilemmas faced by China's national governance. Among them, the land requisition conflicts caused by land requisition issues are more serious. According to the announcement of the Ministry of Land and Resources, in 2017, the competent department of resources filed and investigated 372 illegal cases, ${ }^{1}$ which involved most provinces and regions in China, which involved investigation, listing, supervision, and public notification. It can be seen that the current land-related social incidents have become a common manifestation in various parts of China, especially triggered by land acquisition. Conflict incidents have become one of the most important manifestations of rural mass incidents. Naturally, it should become a typical area for us to analyze the dilemma of national governance. This study believes that relevant systems and regulations have been distorted in the specific land acquisition practices, thereby

\footnotetext{
1Data source: Ministry of Land and Resources Portal: http://www.mlr.gov.cn/zwgk/zytz/201801/t20180118_1 746467.htm。
}

infringing on the China's regulatory capacity, that is, forming a backlash effect on the China's governance capabilities and governance effects, and becoming an important cause of conflicts in land acquisition. In this research, the researcher will analyze the specific implementation status of the national system (mainly related system laws promulgated by the central and all levels of government) in land acquisition from four aspects (mainly based on the actual actions of the local government closest to the system implementation practice) ${ }^{2}$, And discussed the internal logic behind the formation of this situation and the possible path to optimize the practice of national governance.

The rest of the thesis is organized as follows. In Section 2, we reviewed the relevant literature. In Section 3 , we introduced the case and data method. The results and discussion are analyzed in Section 4. The fifth part summarizes the conclusion, and provides a way to solve the dilemma in land expropriation.

\section{Literature Review}

The existing research has done a lot of research on the causes of land expropriation conflict and land expropriation governance dilemma, but after summarizing and classifying, it is found that there are two

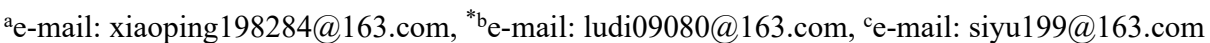


main research perspectives: one is the perspective of institutional deficiency and structural imbalance. It is considered that the imperfect relevant system of national land expropriation and the imbalance of social urban and rural structure are the root causes of land expropriation conflict. For this reason, some suggestions are put forward, such as establishing socialist market-oriented land expropriation system ${ }^{[1]}$, strengthening compensation for land-lost farmers ${ }^{[2]}$, reforming urban and rural household registration system ${ }^{[3]}$, and even revising the relevant provisions in the constitution. This point of view focuses on the consideration of social system and social structure, which is conducive to improving China's existing institutional system and, to a certain extent, safeguarding the relevant rights and interests of farmers. However, it is unable to answer the problem that the land expropriation conflict continues to occur under the premise of the continuous improvement of the land expropriation system. Some scholars believe that even if the land expropriation system continues to be modified, it not effectively eliminate the land expropriation conflict ${ }^{[4]}$. Second, from the point of view of the game among stakeholders, it is considered that the imbalance of game power among the government, farmers and developers leads to conflicts and contradictions in land expropriation ${ }^{[5]}$, and puts forward measures to restore the balance of the game. Most of the research in this part goes deep into the specific choice and action of the game subject, but in the choice of the analysis object, it shows obvious preference for the farmer as the subject, and fails to pay due attention to the specific practice of the local government implementing the system in land expropriation ${ }^{[6]}$.

Regulation ability is an important part of national governance ability, which refers to the ability of state institutions to coordinate social relations by using system and law. Good regulation ability can effectively avoid social conflicts and maintain good social order. The realization of national regulatory capacity depends on the reasonable and adequate supply of relevant systems, but it is not limited to this, because the improvement of the system does not necessarily lead to the practical realization of the will of the state, and its degree of realization is also affected by the specific practice of the system enforcement agencies, that is, the real country is shaped by two elements, namely, concept and practice, and the two will overlap and strengthen each other. It may also repel each other or even destroy each other ${ }^{[7]}{ }^{16}$. In recent years, the continuous frequent conflicts of land expropriation in China have demonstrated this point. With the large-scale promotion of land expropriation in China in the 1990s, the relevant contradictions have become prominent. In order to eliminate the contradiction, China has revised the relevant systems and regulations in the field of land expropriation many times, so there is no institutional root cause of many land expropriation conflicts. In many systems and regulations, the state has regulated the law enforcement, benefit distribution, implementation procedures and information feedback in land expropriation in order to form effective governance. However, some local governments distort the relevant systems to varying degrees in the specific implementation, eat back the ability of the systems and regulations to regulate social relations, and lead to a large number of conflicts in land expropriation. As a result, the state's governance of the conflict of land expropriation has fallen into a practical dilemma. Then the analysis space left for this study lies in the specific implementation of the relevant systems-that is, based on the specific practice of national governance under the relevant systems.

\section{Materials and Methods}

\subsection{Date collection}

The cases mentioned in this study come from official authoritative websites, namely Xinhua net, People's Daily Online, Dahe.com, etc. They collected and analyzed typical events in the field of land acquisition in China in the past ten years (2007-2017). The selection criteria for these cases are officially approved and reported by relevant media have certain authenticity and credibility. Social governance, practical dilemma, innovation path, land acquisition conflict as keywords, a total of 100 land conflict cases are collected and sorted out, among which 79 cases are selected as the research cases of this paper, and these 79 cases are coded and analyzed from 1-79. These cases reflect the types and logicality of conflicts.

\subsection{Methods}

Based on statistical analysis of data, this study divides China's land acquisition conflicts into four types, namely, regulation and backlash on the implementation of land acquisition, regulation and backlash on the distribution method of land acquisition benefits, regulation and backlash on land acquisition procedures, and the regulation and backlash of the feedback methods of land acquisition information are analyzed in detail. In the land acquisition, there have been forced land acquisition, insufficient compensation, procedural violations and no right to speak. This article displays data on the number of incidents and whether they have been resolved. Regarding these four contradictions, they are a display of conflicts about land acquisition in China in recent years. What is regulated by the China and how backlashes have been encountered in specific practices, so as to obtain a percentage of backlashes, that is, what happened rate.

\section{Results \& Discussion}

\subsection{Results}

This article sorts out the 79 cases collected from the four aspects of land acquisition implementation method, benefit distribution method, land acquisition procedure, and information feedback method. Among them, 36 cases were "forced land acquisition" and 16 cases were resolved; "compensation" were 24 cases of "insufficient" and 11 cases that were resolved; 10 cases of "procedural violations" and 5 cases were resolved; 9 cases of "no right 
to speak" and 1 case resolved. After sorting out the contradictions in the four aspects, the incidence of backlash was $45.6 \%, 30.4 \%, 12.7 \%$, and $11.4 \%$. From the chart, we can see the land expropriation conflict incidents and incidence rate in China in recent years, and analyze and display the results of these four aspects.

Table1: Different types of land conflicts.

\begin{tabular}{lcc}
\hline \multicolumn{1}{c}{ types } & number & solve \\
\hline Forced land acquisition & 36 & 16 \\
Less compensation & 24 & 11 \\
Procedural violation & 10 & 5 \\
No right to speak & 9 & 1 \\
\hline
\end{tabular}

Table2: Arrangement of the proportion of regulation and counter-attack in land expropriation.

\begin{tabular}{|c|c|c|c|}
\hline & Regulation & Rejection & Incidence \\
\hline Implement way & Prohibition of abuse of power & Forced land expropriation & $45.6 \%$ \\
\hline Distribution of benefits & acquisition & Resell at a high price to make a & $30.4 \%$ \\
\hline Land acquisition procedures & compensation level & difference & $12.7 \%$ \\
\hline Information feedback method & $\begin{array}{l}\text { Two registrations, one announcement } \\
\text { Construct feedback channels for } \\
\text { farmers' }\end{array}$ & $\begin{array}{l}\text { No announcement or simplified } \\
\text { procedures } \\
\text { No right to speak }\end{array}$ & $11.4 \%$ \\
\hline
\end{tabular}

\subsubsection{Regulation and counter-expropriation of the way of law enforcement of land expropriation}

Regarding the law enforcement methods in land acquisition, the three versions of the Land Management Law in 2004, 2012 and 2017 have all clearly stipulated. In particular, warnings are given to the abuse of power in land acquisition law enforcement, which constitutes a crime. If criminal responsibility is investigated and does not constitute a crime, administrative sanctions must be imposed in accordance with the law. As a supplement to the Land Law, the central government and governments at all levels have successively issued some policies and regulations related to land acquisition law enforcement to restrict law enforcement, as in 2011, The notice issued by the Ministry of Land and Resources in 2013 all mentioned that the implementation of land acquisition and demolition must be carried out in accordance with the law, and that the illegal land acquisition and the violation of the interests of farmers must be held accountable. However, the existing system's regulation of land acquisition law enforcement methods has been distorted to varying degrees in real land acquisition practices. Researchers have analyzed 79 typical land acquisition incidents reported by the media in China in the past decade and found that: the use of intimidation and threats Such phenomena as verbal violence or the direct use of black and gray forces to forcibly expropriate land ${ }^{[8]}$ have appeared many times, accounting for $45.6 \%$ of reported land expropriation incidents. Violent land expropriation is indeed speeding up the process of land expropriation with the highest efficiency, but in the long run, these Law enforcement actions have led to social tensions in land acquisition and have become the fuse that triggered conflicts in land acquisition.

\subsubsection{Regulation and counter-expropriation of the distribution of land acquisition benefits}

The distribution of benefits is the core of the issue of land acquisition. Whether the distribution method is reasonable or not directly affects the social relations in land acquisition. On the one hand, the distribution of land acquisition benefits should be tilted to the landexpropriated farmers, especially the disadvantaged groups, under the premise of fairness. On the other hand, the distribution of land requisition benefits should reflect the dynamics and variability, and gradually increase the compensation standards for land-expropriated farmers. For example, in 2004, it was required that multiple factors should be flexibly considered when formulating comprehensive land prices for districts. In 2010, it was further proposed. It is necessary to establish a dynamic adjustment mechanism for land acquisition compensation standards and gradually increase the level of land acquisition compensation. However, some local governments failed to implement the above principles well, and tilted the balance of interest to the local governments themselves. The specific actions were to expropriate rural land at low prices and sell them to real estate developers at high prices, which greatly undercut the existing system. The ability to regulate the profit distribution model hinders the realization of national governance capabilities in rural society, and has become another cause of disorder and conflict in rural society.

\subsubsection{Regulation and counter-expropriation of Land expropriation procedure}

Land requisition is an administrative act of the government, which inevitably involves the regulation of the way of interaction between the administrative subject and the administrative object, and whether the land requisition procedure is reasonable or not directly affects 
the specific situation of the interaction of all parties. The "Regulations for the Implementation of the Land Management Law" revised in 2014 clearly stipulate that two announcements and one registration are involved in all important aspects of land acquisition. It involves all important links in land acquisition, among which "two announcements" are announcements on land acquisition plan and land acquisition compensation and resettlement plan before land acquisition, and "one registration" is registration of land acquisition compensation for owners and users of expropriated land before land acquisition. China uses land acquisition procedures to regulate the interaction process of all parties. However, in the specific implementation, the practice of not making announcements or simplifying and formalizing the announcement procedures by local governments in land acquisitions is widespread. According to the statistics of researchers, nearly half of the land acquisition conflicts reported by the media in the past ten years are This is caused by the failure of the local government to strictly implement the land requisition procedures, such as the land requisition incident in Henan Lingbao province and Tieling Liaoning province. National governance practices will face greater difficulties.

\subsubsection{Regulation and counter-expropriation of the feedback of land expropriation information}

In order to better regulate the social relations in land acquisition, China's relevant systems and regulations have also made clear provisions on the information feedback method in land acquisition. For example, the 2002 Letters and Visits Regulations proposed that citizens can use various forms such as letters and telephones to provide information to land resources at all levels. The management department reported problems and reported illegal activities in land acquisition; the guidance issued by the Ministry of Land and Resources in 2004 advanced the announcement of land acquisition before the approval of land acquisition, and added a confirmation link. If farmers have objections, they must be organized in time Hearing; In 2014, the "Land Expropriation Information" column and channels for the active disclosure of information in various media. However, in the practice of land acquisition, it is very common for farmers to be deprived of their right to speak. However, in the practice of land requisition, it is very common for farmers to have their right to speak. The specific manifestation is that the local government does not allow villagers to petition during land requisition, and even encircles and intercepts petitioning villagers, and uses a "blocking" method to coordinate the government and farmers in land acquisition. This not only severely damaged the information feedback loop built by the state, but also led to farmers' opinions. The inability to be effectively expressed has led to a deeper governance dilemma.

\subsection{Discussion}

The specific practice of taking local government actions as the main factor in land expropriation has eroded the national regulatory capacity and triggered land expropriation conflicts. For this reason, the researchers believe that there are mainly the following three logics:

\subsubsection{The "independent space" of the local government formed under the special structural system is the premise.}

Tocqueville pointed out: "A central government, no matter how smart and competent it is, can't rely on itself to understand all the details of life in a big country" [9]. On this basis, China's administrative system has formed a complex bureaucratic structure of "dividing up and down", and the central and local authorities are divided. Under the unified leadership of the central government, the principle of local autonomy and enthusiasm is fully exerted. The local government has a certain autonomous space, which makes it possible for it to deviate from the policy in actual operation and increases the uncertainty of the realization of the national will at the grass-roots level. The implementation of a decision has to go through multiple levels, and each level will interpret the policy twice, which will make the policy constantly deformed and distorted, and finally lead to a huge gap between the norms of the formal system in the relationship between the state and society and the actual operation ${ }^{[10]}$. The local government is a rational actor, and the capital effect brought by land circulation drives the local government to screen again to meet its own needs, such as bypassing the relevant procedures in land expropriation, damaging farmers' interests in the distribution of land expropriation benefits, tilting towards the local government, using land resources to obtain additional income, which leads to many social conflicts, and the national governance capacity will be seriously countered.

\subsubsection{The "three-dimensional competition" of local government formed under the special institutional environment is the internal driving force}

The institutional environment of local governments in China includes the performance evaluation system, the accountability system of local officials, and the one-vote veto system. Among them, economic development is at the core, and officials at all levels present a "promotional championship" style of GDP [11] Increase competition. Land transfer is an important channel for local governments to bridge the financial gap. Using land to obtain income ${ }^{[12]}$, for this reason, distortion of the system in land acquisition has become a high probability event, such as illegal land acquisition in order to find new economic growth points. Or it is intended to simplify the regulations on land acquisition procedures in relevant systems, or to attract more land value-added income into local finances, which distorts the original intention of the central government to achieve rural development through land acquisition, and so on. The system with economic development as its core is also coordinated by specific systems. On the one hand, under the existing official evaluation system based on economic development performance and an accountability system that is 
accountable to the authorities, local governments will choose to help them The behavior of political survival without the intention to provide better public services ${ }^{[13]}$. As a result, local governments have formed the characteristics of requisitioning land requisitioning vigorously and resettlement compensation, such as in Kunming fishing village, villagers' land in 2006 It has been expropriated, but the compensation was issued only in 2009, and the compensation price has not increased with the skyrocketing local housing prices. It can be seen that what the Chinese land law enforcement agencies really want to accomplish is the central work goal of the system $^{[14]}$.On the other hand, under the one-vote veto system of "stability overriding everything", social stability is an important task of local governments ${ }^{[15]}$. In the face of conflicts in land acquisition, local governments try their best to achieve the apparent stability goals, which leads to conflicts in land acquisition Worsening and serious governance dilemmas.

\subsubsection{The "action dilemma" of the local government formed in the special local situation is the intensifier.}

No matter how perfect the system is, it must be placed in a specific situation to test its feasibility. The particularity of the region increases the possibility that local governments will change the central directive to adapt to the special conditions of the region. ${ }^{[7] 124}$. In land acquisition, the local government of China. The local situation facing rural society is a relatively special field: First, the autonomy is strong, and farmers have irrational trust in their family members, while outsiders remain extremely vigilant. This trust system is the villagers provided a simple solution to the trust problem, which will greatly affect the farmers' recognition of land acquisition at the beginning of land acquisition. Secondly, the ambiguity is strong. The ambiguity of rural society is mainly manifested in the ambiguity of land rights and responsibilities. China's laws do not thoroughly clarify the issue of land property rights. Farmers have paid a lot of labor and must think that they are the real owner of the land. However, this cognition is contrary to the legal view that farmers only have land management rights. This has led to large differences between local governments and farmers in the specific implementation of land acquisition or not, and how to allocate the benefits of land acquisition. At last, the diversity of differentiation. When rural areas are faced with land acquisition disputes, the action choices of different farmers are very different, which leads to constant conflicts in land acquisition. Some farmers tend to adopt other non-institutional methods to deal with it, making it easy for local governments to fall into confusion when intervening in rural land acquisition situation. In the face of this dilemma, local governments simplify land acquisition procedures, ignore farmers' feedback, and force or even violently promote land acquisition have become a fast-cut messy and efficient administrative method. Accordingly, land acquisition conflicts are inevitable.

\section{Conclusions}

With the frequent occurrence of land expropriation conflicts, China has perfected relevant systems. Therefore, this article believes that there is no reason for the lack of system, but problems in the implementation of the system. In the case of China's simplified administration and decentralization, local governments have a certain degree of autonomy. The pressure of economic assessment has caused local governments to distort the policies of their superiors in the implementation of the system, tilting the balance of interests to themselves, and infringing on the interests of farmers. A series of land acquisition conflicts were caused. Under the "Internet + " social governance modernization system, the improvement of system execution is critical for future development. It is necessary to strengthen the China's ability to re-regulate social relations, so as to break through the practical difficulties in governance, reduce conflicts, and modernize China's social governance. It has a positive meaning.

In the context of "Internet +", social governance is particularly important. "Internet + " provides us with a new perspective. There are three aspects to the innovation path of social governance and emergency management. Firstly, the system must be optimized, and the supervision and regulation in the implementation of the system must be emphasized. The first is to strengthen the central government. Directly under the supervision mechanism, weaken the autonomy of local governments on major issues. The second is to strengthen the social supervision network, open up the supervision channels of the government, society, and the Internet to supervise and regulate local governments. Secondly, it emphasizes the optimization of the system and the establishment of a scientific and reasonable official performance appraisal system. On the other hand, it strictly controls the establishment of one-vote veto projects and attaches importance to public opinion. Finally, it emphasized that the system fits the flexible setting of the local field, and the specific policy design is combined with the flexible design plan of the local situation to achieve the principle of combining totality and refinement.

\section{Acknowledgments}

National Social Science Foundation Youth Project "Research on the Mode and path of Xin Xiang Xian's participation in Rural Community Governance" (18CSH010)

\section{References}

1. Luo Tingting etal. thinking on establishing the dominant position and improving the multi-guarantee mechanism of land-expropriated farmers $[\mathrm{J}]$. China agricultural resources and regionalization, 2017(10):144-151.

2. Wang, Yuxin .Effect of Land Expropriation on LandLost Farmers'Health: Empirical Evidence from Rural China. 2019 (16) : 1-12 
3. Zhu Tianzhi. Social security of landless peasants and long-term governance of land-expropriated mass incidents [J]. Contemporary Economic Management, 2014(10):40-44.

4. He Xuefeng. How to understand the conflict of land expropriation-Also on the revision of Land Administration Law [J]. Ideological Front, 2018(3):111-117.

5. Huihuang Lin, Ouyang Jing. Power Game and System Reconstruction in Land Expropriation [J]. Contemporary Finance and Economics, 2015(6):1425.

6. Tan Shu-kui, Tu Shan. Game Analysis of Stakeholders in Land Expropriation Conflict: A Case Study of Local Government and Land-lost Farmers [J]. china land science, 2009(11):27-31.

7. [ America] Joel S. Migdale. The state in society-how the state and society change and form each other [M]. Translated by Li Yang, etc. Nanjing: Jiangsu People's Publishing House, 2013.

8. Liu Jianping, Tian Miao. Analysis on the behavioral characteristics and formation mechanism of gray forces in the field of land acquisition and demolition[J]. Journal of Huazhong University of Science and Technology (Social Science Edition), 2015(3): 31-37.

9. Toke Weier. On American Democracy (Volume 1) [M]. Translated by Dong Guoliang.Beijing:The Commercial Press, 1988: 105.

10. Wang Xinxian. Contemporary China's National Capability and Social Stability: Concurrently Discussing the Meaning of "Social Management Innovation" Han[J].China Governance Review,2012(2):54-87.

11. Zhou Li' an. Research on the promotion championship model of local officials in China [J]. Economic Research, 2007 (7): 36-50.

12. Rui-fencao.How imbalanced land development influences local fiscal conditions? A case study of Hubei province, China, land use policy, volume 99, 2020 (105086): 3

13. Research Group of Economic Research Institute of National Development and Reform Commission: Sub-report 13: Research on Government Reform with National Capacity Reconstruction as the Core [J]. Reference for economic research. 2012 (43): 59-61.

14. He Yanling. China's land law enforcement swing phenomenon and its explanation [J]. Legal Research, 2013(6):61-72.

15. Yang Dalu, Yang Fulu. Behavior Logic and Governance of Local Government's Social Stability under the New Situation [J]. Theoretical Guide, 2013. 